\section{sciendo CALCULATION OF OPERATIONAL INDICATOR EEOI FOR SHIPS DESIGNED TO OTHER PURPOSE THAN TRANSPORT BASED ON A RESEARCH - TRAINING VESSEL}

DOI 10.2478/ntpe-2018-0041

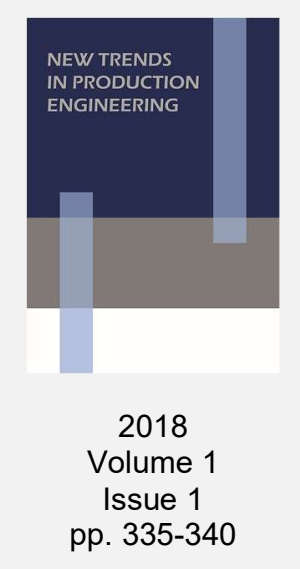

Volume 1

pp. 335-340

\author{
MSc. Katarzyna Prill, MSc. Karol Igielski \\ Maritime University of Szczecin, Poland
}

\begin{abstract}
Applying the Energy Efficiency Operational Indicator as a tool for monitoring the energy efficiency of ships performing other functions or tasks than transport is a problem in the proper assessment of the $\mathrm{CO}_{2}$ emitted by the vessel during its operation. The analysis of 30 voyages of the research-training vessel showed that the vessel Energy Efficiency Operational Indicator is higher than for transport vessels in the world fleet. The authors suggest that the term „performed transport work” in the indicator calculation method recommended by the International Maritime Organization needs to be modified in terms of operational parameters of this type of ships.
\end{abstract}

Keywords: Vessel energy efficiency, $\mathrm{CO}_{2}$ emission, research - training vessel, EEOI, operational indicator

\title{
INTRODUCTION
}

Maritime transport is one of the most efficient transportation branches. Goods having various physical and chemical properties are transported by ships over long distances. This phenomenon determines continuous changes both in terms of exploitation, ship structure, its dimension, propulsion system and operational capacity of transshipment ports, and mainly affects that goods are transferred faster from the producer to the recipient. Determining that the goods are transported in as large quantity as possible, in the shortest possible time involves increasing the speed of the ship and thereby intensifying the combustion process of fuel. The result of same is releasing the remains of the process to the environment i.e. $\mathrm{CO}_{2}$ and other greenhouse gas. MacLachlan (MacLachlan, 2005) believes that the top 15 largest ships would emit as much greenhouse gasses as all the $\mathbf{7 8 0}$ million cars. It should be noted that there are up to 100,000 working vessels and shipping brings us $90 \%$ of world trade (MacLachlan, 2005). The ships travel huge distances and as pointed out by Buhaug et al (Buhaug et al, 2009) every ship type may be characterized by a different $\mathrm{CO}_{2}$ emission level, which results in significant increase of the gas emission to the atmosphere.

The matter of effects caused by the greenhouse gas emissions to the atmosphere being a result of a ship operation has been analyzed by scientists for dozens of years. Scientific studies and analyses have shown that shipping makes up around $3 \%$ of global $\mathrm{CO}_{2}$ emissions (Amstrong and Banks, 2015), while Smith et al. (MEPC, 2014) forecast that these emissions are expected to increase from the 2012 levels by $50-250 \%$ by 2050 . In recent years, the IMO is mainly focused on developing a multi-dimensional policy for the reduction of $\mathrm{CO}_{2}$ emitted by ships to the atmosphere. This activity has been imposed by the requirement included in Art. 2 of the United Nations Framework Convention on Climate Change (UN, 1997). The paper indicates that the responsibility for implementing activities related to the reduction of $\mathrm{CO}_{2}$ emission in the shipping industry has been assigned to the IMO. Since the Kyoto Protocol adoption, the Marine Environment Protection Committee has been working on developing the solutions enabling to improve the energy efficiency of ships. The main MEPC assumption was to develop tools aimed at solving the problem at every stage of ship operation, commencing on the design phase and proceeding trough the operational stage. 
As a result, the MEPC developed tools which when combined with one another, would reduce $\mathrm{CO}_{2}$ emission gradually, and, consequently, would reduce the global air temperature to the agreed in 2009 temperature of $2^{\circ} \mathrm{C}$ above the temperature in the pre-industrial era (MEPC, 2014). Among the above-mentioned solutions, the following ones have been included:

1. Energy Efficiency Design Index (EEDI) - MEPC Circ.681, 682, 212(63) (MEPC, 2012), 213(63), 215(63), is the regulation implemented for new vessels. The EEDI was developed and implemented as a response to the need to meet the technical and structural requirements of ships at the design stage which would result in an increased energy efficiency of the fleet as a whole (Szczepanek and Rajewski, 2015).

2. Ship Energy Efficiency Management Plan (SEEMP) - MEPC Circ.683, 213(63). During the works aimed at improvement of the energy efficiency, the IMO proposed a system approach. The approach purpose is to increase the ship energy efficiency by developing specific measures by the shipowner on the particular ship, which would lead to the reduction of $\mathrm{CO}_{2}$ emission. The SEEMP was adopted (MEPC, 2012) as a mandatory tool under MARPOL Annex VI reg. 22 as amended and entered into force on $1^{\text {st }}$ January 2013.

3. Energy Efficiency Operational Indicator (EEOI) - MEPC Circ.471, 684. The main goal of the indicator is to improve the energy efficiency of a ship during a travel by determining the ratio of the mass of $\mathrm{CO}_{2}$ emitted per a specified a unit of transport work (MEPC, 2009). Determining the EEOI is voluntary and should be calculated on the grounds of actual operational data monitored and recorded during the voyage.

The EEOI indicator is presented in detail in the following section of the paper (section 2). Section 3 is a discussion on the application of the current method for determining the EEOI for a ship to the research - training vessel specification.

\section{OPERATIONAL INDICATOR OF SHIP ENERGY EFFICIENCY}

The IMO has adopted the EEOI as a tool aimed at supporting the process of limiting and the reduction of $\mathrm{CO}_{2}$ emission by the ships in operation. The indicator has been defined as a ratio of the mass of $\mathrm{CO}_{2}$ emitted per a specified work unit e.g. $\mathrm{CO}_{2}[\mathrm{t}] /(\mathrm{t} / \mathrm{Nm}), \mathrm{CO}_{2}[\mathrm{t}] /(\mathrm{TEU} / \mathrm{Nm})$, etc. (Tran, 2017).

$$
E E O I=\frac{\text { actual } \mathrm{CO}_{2} \text { emission }}{\text { performed transport work }}
$$

The EEOI represents the ship energy efficiency in a defined time. It is the most commonly used to calculate the energy efficiency per a voyage, a year or a specific operational cycle. In order to determine the EEOI for a particular period (for a voyage), according to the MEPC.1/Circ. 684, the following formula should be applied:

$$
E E O I=\frac{\Sigma_{j} F C_{j} \times C_{F j}}{m_{\text {cargo }} \times D_{j}}
$$

where:

$j-$ fuel type;

$F C_{j}-$ mass of consumed fuel $j$ at voyage;

$C_{F j}$ - fuel mass to $\mathrm{CO}_{2}$ mass conversion factor for fuel $j$;

$m_{\text {cargo }}$ - cargo carried (tonnes) or work done (TEU or passengers) or gross tonnes for passenger ships;

$D$ - distance in nautical miles corresponding to the cargo carried or work done.

In order to calculate the EEOI for a longer period of time e.g. a year, a quarter, all voyages of the ship in that period should be summed up along with those where the ship did not carry any cargo.

\section{CALCULATING EEOI FOR RESEARCH - TRAINING VESSEL USING A STANDARD METHOD}

The IMO listed 7 types of ships in the Guidelines for voluntary use of the ship Energy Efficiency Operational Indicator (EEOI) (MEPC, 2012): dry cargo carriers, tankers, gas tankers, containerships, ro-ro cargo ships, general cargo ships, passenger ships for which the indicator is recommended. The list does not include the vessels the aim of which excludes transport of 
goods and passengers i.e. fishing vessels, offshore vessels, specialised and research vessels, training vessels and coastal shipping vessels. Periodic reports on the energy efficiency of the global fleet take into account additional ship types (MEPC, 2014, UCL E.I., 2015), but the IMO focused mainly on vessels transporting cargo or passengers which are reflected in the formula by (2) $m_{\text {cargo. }}$ In the view of the above, it may become problematic to adjust the recommended formula (2) to the specification of the ships which do not transport cargo or passengers, but they are operated intensively, emitting $\mathrm{CO}_{2}$ (Lützen at al., 2017).

In order to compute the EEOI using the standard method specified in formula (2), 30 voyages of the research-training vessel taken in 2015 and 2016 were selected. The voyage was defined a ship trip in a period of time determined by education program and maritime training program, started and finished in Szczecin port, during which the tasks related to the implementation of the maritime training program and/or the research work are performed. The voyage duration includes stops at anchorages, ports, roadsteads etc. The $m_{\text {cargo }}$ is considered as a total weight of students and scientists divided by gender and participating in the voyage, i.e. an average weight of a man $-88.8 \mathrm{~kg}$, an average weight of a woman $-76.4 \mathrm{~kg}$ (U.S.HDHS, 2016) along with a luggage of an average weight of $20 \mathrm{~kg}$ per person. The maximum amount of people that may be on board (excluding the crew) equals to 38 . The vessel uses only MGO DMA fuel of the density of $856.8 \mathrm{~kg} / \mathrm{m}^{3}$ at the temperature of $15^{\circ} \mathrm{C}$ and $0.07 \%$ sulphur content. Therefore, according to the MEPC.1/Circ.684, $C_{F}$ for fuel is 3.206 . Table 1 presents extraction from data used for research purposes and the EEOI indicator calculated using a standard method.

Table 1.

Calculation of EEOI for research - training vessel - standard method (extraction from data).

\begin{tabular}{|c|c|c|c|c|c|c|c|}
\hline \multirow[t]{2}{*}{$\begin{array}{l}\text { Voyage } \\
\text { number }\end{array}$} & \multirow[t]{2}{*}{ Period } & \multirow[t]{2}{*}{$\begin{array}{l}\text { Distance } \\
{[\mathrm{Nm}]}\end{array}$} & \multicolumn{2}{|c|}{$\begin{array}{c}\text { Number } \\
\text { of } \\
\text { persons }\end{array}$} & \multirow[t]{2}{*}{$\begin{array}{c}\text { Fuel } \\
\text { consumption [t] }\end{array}$} & \multirow[t]{2}{*}{$\begin{array}{c}\mathbf{m}_{\text {cargo }} \\
{[t]}\end{array}$} & \multirow[t]{2}{*}{$\begin{array}{c}\text { EEOI } \\
{\left[\mathrm{tCO}_{2} /(\mathrm{t} x\right.} \\
\mathrm{Nm})]\end{array}$} \\
\hline & & & $\mathrm{K}$ & $\mathbf{M}$ & & & \\
\hline 1 & $16.02-27.02 .2015$ & 524.3 & 7 & 28 & 12.85 & 3.7212 & $2.112 \mathrm{E}^{-02}$ \\
\hline 2 & $02.03-13.03 .2015$ & 646 & 9 & 26 & 12.38 & 3.6964 & $1.662 \mathrm{E}^{-02}$ \\
\hline 3 & $17.03-23.03 .2015$ & 495 & 9 & 25 & 11.48 & 3.5876 & $2.073 \mathrm{E}^{-02}$ \\
\hline 4 & $14.04-22.04 .2015$ & 499 & 4 & 29 & 9.94 & 3.5408 & $1.804 \mathrm{E}^{-02}$ \\
\hline 8 & $09.06-12.06 .2015$ & 441.8 & 7 & 27 & 5.91 & 3.6124 & $1.187 \mathrm{E}^{-02}$ \\
\hline 9 & $12.06-21.06 .2015$ & 287.5 & 7 & 27 & 8.91 & 3.6124 & $2.750 \mathrm{E}^{-02}$ \\
\hline 10 & $30.06-24.07 .2016$ & 834.1 & 18 & 17 & 21.2 & 3.5848 & $2.273 \mathrm{E}^{-02}$ \\
\hline 12 & $24.08-28.08 .2015$ & 167.7 & 7 & 25 & 4.8 & 3.3948 & $2.703 \mathrm{E}^{-02}$ \\
\hline 13 & $03.09-04.09 .2015$ & 128 & 13 & 25 & 4.28 & 3.9732 & $2.698 \mathrm{E}^{-02}$ \\
\hline 14 & $27.09-01.10 .2015$ & 472.5 & 0 & 24 & 35.9 & 2.6112 & $9.329 \mathrm{E}^{-02}$ \\
\hline 15 & $19.10-08.11 .2015$ & 280.5 & 2 & 30 & 12.08 & 3.4568 & $3.994 \mathrm{E}^{-02}$ \\
\hline 19 & $14.04-19.04 .2016$ & 396,7 & 9 & 19 & 12.3 & 2.9348 & $3.387 \mathrm{E}^{-02}$ \\
\hline 20 & $26.04-06.05 .2016$ & 303.6 & 3 & 26 & 8.6 & 3.118 & $2.913 \mathrm{E}^{-02}$ \\
\hline 22 & $25.05-03.06 .2016$ & 145.3 & 8 & 22 & 6.58 & 3,1648 & $4.588 \mathrm{E}^{-02}$ \\
\hline 23 & $06.06-16.06 .2016$ & 609 & 7 & 29 & 12.9 & 3.83 & $1.773 \mathrm{E}^{-02}$ \\
\hline 25 & $05.07-28.07 .2016$ & 276.1 & 9 & 26 & 11.91 & 3.6964 & $3.741 \mathrm{E}^{-02}$ \\
\hline 26 & $11.08-19.08 .2016$ & 857.5 & 12 & 23 & 19.03 & 3.6592 & $1.944 \mathrm{E}^{-02}$ \\
\hline 27 & $27.09-13.10 .2016$ & 315 & 9 & 29 & 10.16 & 4.023 & $2.571 \mathrm{E}^{-02}$ \\
\hline 28 & $18.10-21.10 .2016$ & 170 & 2 & 22 & 7.88 & 2.5864 & $5.746 \mathrm{E}^{-02}$ \\
\hline 30 & $05.12-09.12 .2016$ & 172 & 0 & 28 & 7.97 & 3.0464 & $4.876 \mathrm{E}^{-02}$ \\
\hline
\end{tabular}

Source: Author's elaboration

The EEOI for 30 voyages is in the range from $1.187 \mathrm{E}^{-02}$ for voyage 8 to $9.329 \mathrm{E}^{-02}$ for voyage 14 . During the analysis, it has been noted that fuel consumption for voyage 14 definitely deviates from average consumption during the studied period. Due to the fact that it is not possible to confirm that the specified data regarding fuel consumption during the voyage is correct, the authors decided to eliminate voyage 14 from the studies. Given the above, the EEOI is in the range from $1.187 \mathrm{E}^{-02}$ for voyage 8 to $5.746 \mathrm{E}^{-02}$ for voyage 28 . When compared to other available research (MEPC, 2014, UCLEI, 2015), the values of the EEOI for the analyzed vessel achieve high values i.e. $\mathrm{E}^{-02}$. This situation is due to the fact that when compared with other cargo ships, $m_{\text {cargo }}$ of the research subject reaches low values and is in the range of $2.48 \mathrm{t}-4.52 \mathrm{t}$. 
Figure 1 presents an attempt to indicate the relation between $m_{\text {cargo }}$ and the EEOI for a particular voyage.

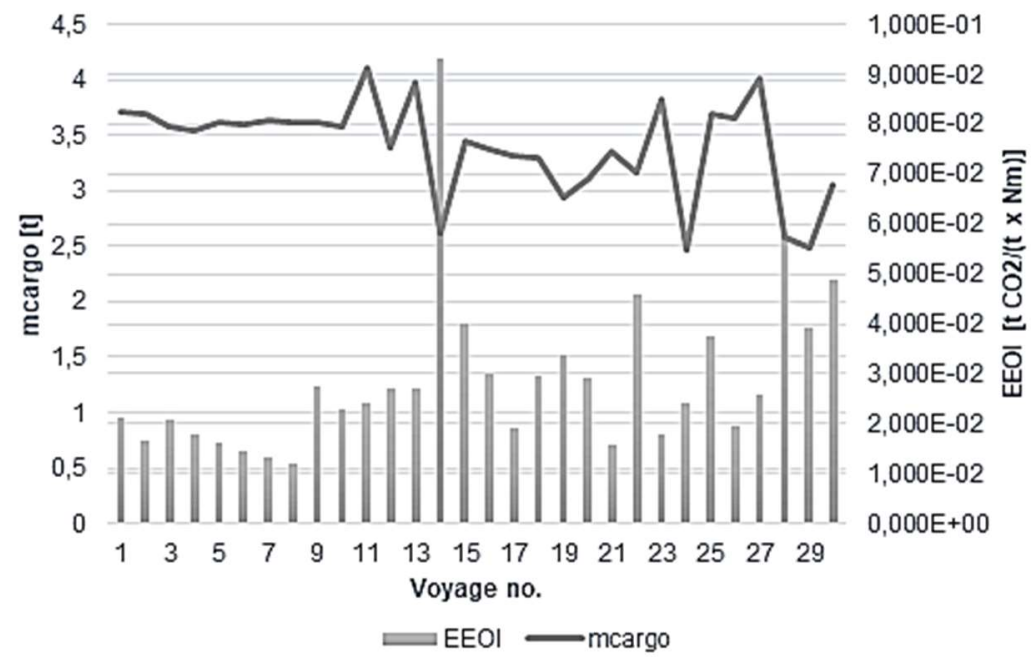

Source: Authors' elaboration.

As it may be noted, there is no direct relation between $m_{\text {cargo }}$ and the EEOI. This fact is proven by the analysis of voyages $1-10$, where $m_{\text {cargo }}$ has the value close to the limit of 0.2 ton, while the indicator values are within the range of $1.32 \mathrm{E}^{-02}-2.11 \mathrm{E}^{-02}$. Another example proving this assumption in voyage 11 during which $m_{\text {cargo }}$ reached the maximum value through all studied voyages i.e. $4.11 \mathrm{t}$ and the EEOI was determined at the level of $2.420 \mathrm{E}^{-02}$.

Figure 2 presents the relations between the distance traveled $D[\mathrm{Nm}]$ during a particular voyage and the EEOI.

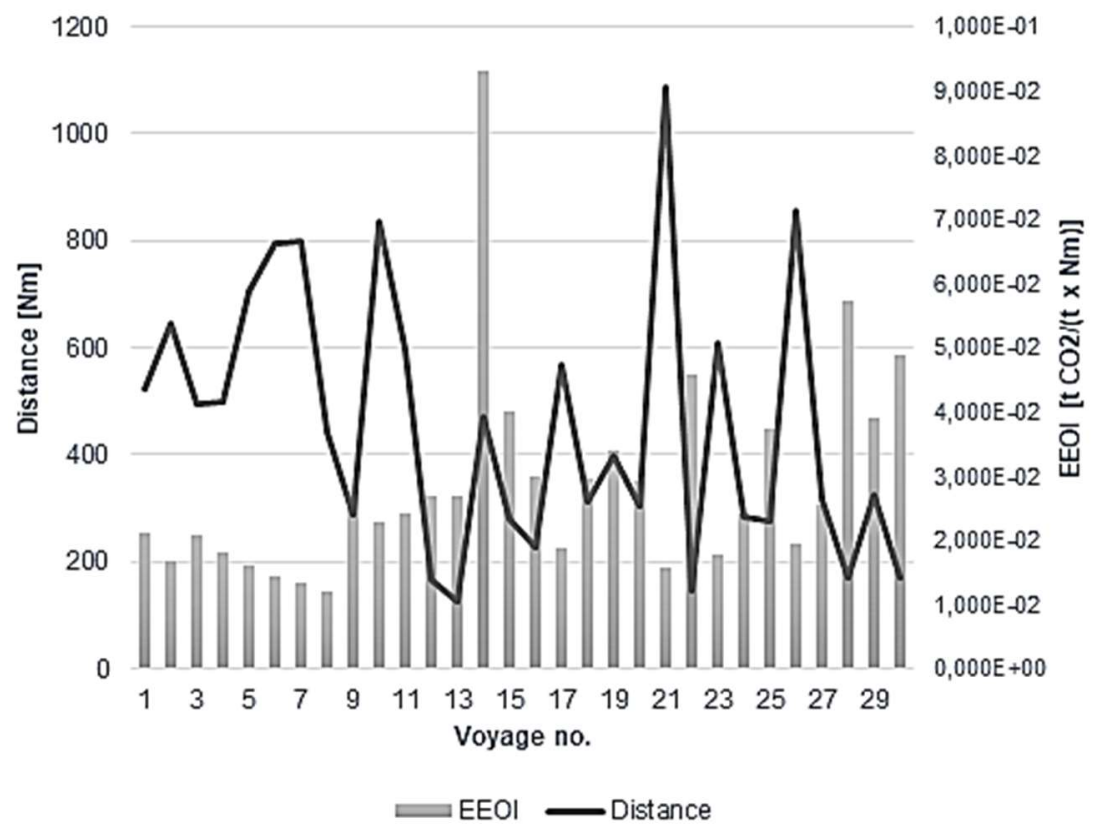

Fig. 2. Relation between distance $D$ and the EEOI during a particular voyage. Source: Authors' elaboration.

\section{DISCUSSION}

The analysis showed that in the case of ship voyage the distance of which exceeds $450 \mathrm{Nm}$, the $\mathrm{EEOI}$ is in the range of $1.325 \mathrm{E}^{-02}-2.112 \mathrm{E}^{-02}$. For the remaining voyages, shorter than $450 \mathrm{Nm}$, the indicator values are higher. The authors state there is a relation between short distances and high values of operational efficiency index. This is related to the average vessel speed 
during the voyage. The analysis of the ship Log Books proves the fact that in these cases the vessel performed intensive maneuvers with high courses and speed variability. And hence, the fuel consumption significantly increased.

\section{CONCLUSIONS}

The above study showed that the standard method to determine the EEOI may not be applied for the research - training vessel. The calculation outcomes indicated significantly higher EEOI when compared with cargo ships. This is mainly caused by $m_{\text {cargo }}$ index. Due to the nature of navigation of the research - training vessel, it is unjustified to consider the number of students and researchers as a load. The second factor that affects negatively the EEOI is fuel consumption. It should be noted that vessels of this type rarely travel on the exactly specified routes with a specifically determined speed. As far as the studied vessel is concerned, one may consider the activities of the vessel as maneuvering exercises which were characterized by high variability of speed and courses which in turn resulted in increased fuel consumption. The characteristic of the research of the vessel requires paying attention to maintain navigational and maneuvering parameters with particular regard to keep appropriate, specific speed during measurements instead of being focused on economic fuel management. The authors believe that it is necessary to develop new approach to the EEOI for research ships. In particular, new indicators should be developed or criteria for performed transport work, that would be suitable for a particular vessel type, should be indicated. This would enable to optimize the process of ensuring appropriate energy efficiency of the ship in terms of its operation.

\section{ACKNOWLEDGEMENTS}

This research outcome has been achieved under the research project no. 2/S/IESO/2014 financed from a subsidy of the Polish Ministry of Science and Higher Educations for statutory activities of Maritime University of Szczecin.

\section{REFERENCES}

Amstrong V. N. and Banks C. (2015). Integrated approach to vessel energy efficiency, Ocean Engineering, 110, pp. 39-48.

Buhaug, Ø. Corbett, J.J., Enderesen, Ø., Eyring, V., Faber, J. Hanayama, S., Lee, D.S., Lee, D., Lindstad, H.Markowska, A.Z., Mjelde, A., Nielsen, D., Nilsen, J., Pålsson, C., Winebrake, J.J., Wu, W. and Yoshida, K., (2009). Second IMO GHG Study 2009,

Lützen M., Mikkelsen L.L., Jensen S., and Rasmussen H.B. (2017). Energy Efficient of working vessels - A Framework, Journal of Cleaner Production, 143, pp. 90-99.

MacLachlan, S, (2005).Carbon emissions all at sea: why was shipping left out if the Paris Climate Agreement?, OECD INSIGHTS [online]. Available at: http://oecdinsights.org/2016/05/04/carbon-emissions-all-at-sea-why-was-shipping-left-outof-the-paris-climate-agreement/ [Accessed: 24 Mar. 2017].

MEPC 1./Circ.684. (2009). Guidelines for voluntary use of the ship energy efficiency operational indicator (EEOI).

MEPC 1./Circ.212(63). (2012). Guidelines on the method of calculation of the attained energy efficiency design index (EEDI) for new ships.

MEPC.213(63). (2012). Guidelines for the development of a Ship Energy Efficiency Management Plan (SEEMP).

MEPC 67/INF.3. (2014). Smith, T.W.P. et al. Third IMO GHG Study 2014 - Final Report.

Szczepanek M. and Rajewski P. (2015). How to improve energy efficiency of the polish fishing vessels due to energy audit implementation, Mechanism and Machine Theory Problems of Mechanics, 58, pp. 83-95.

Tran, T.A., (2017). A research on the Energy efficiency operational indicator EEOI calculation tool on M/V NSU JUSTICE of VINIC transportation company, Vietnam, Journal of Ocean Engineering and Science, pp. 1-6.

UCL ENERGY INSTITUTE, (2015). The Existing Shipping Fleet's $\mathrm{CO}_{2}$ Efficiency, Executive Summary and Main Report March 2015.

U.N. Framework Convention on Climate Change, (1997). [online] Available at:https://www.mos.gov.pl/g2/big/2009_04/8e0542a94447bcaf09cf7d2e2ce38d36pdf [Accessed: 24 Mar. 2017]. 
U.S. Department of Health and Human Services (2016). Vital and Health Statistics, Anthropometric Reference Data for Children and Adults 2010-2014

Date of submission of the article to the Editor: 06/2018

Date of acceptance of the article by the Editor: 08/2018 